\title{
Influence of oocyte-secreted factors and culture duration on the metabolic activity of bovine cumulus cell complexes
}

\author{
M. L. Sutton ${ }^{1}$, P. D. Cetica ${ }^{2}$, M. T. Beconi' ${ }^{2}$, K. L. Kind ${ }^{1}$, R. B. Gilchrist ${ }^{1}$ \\ and J. G. Thompson ${ }^{1 *}$ \\ ${ }^{1}$ Reproductive Medicine Unit, Department of Obstetrics and Gynaecology, University of Adelaide, \\ The Queen Elizabeth Hospital, Woodville Road, Woodville, South Australia, 5011, Australia; \\ and ${ }^{2}$ Area of Biochemistry, School of Veterinary Sciences, University of Buenos Aires, \\ Chorroarin 280 (C1427CWO), Buenos Aires, Argentina
}

\begin{abstract}
Intracellular communication between the cumulus cell complex and the oocyte is essential for numerous processes during oocyte maturation. The aim of this study was to determine the interaction between oocyte-secreted factors and the metabolic activity of bovine cumulus cell complexes during in vitro maturation (IVM). Cumulus-oocyte complexes (COCs) were aspirated from ovaries derived from an abattoir and divided into four treatment groups: (i) intact COCs, (ii) oocytectomized complexes (OOX), in which the ooplasm was microsurgically removed, (iii) OOX co-cultured with denuded oocytes $(O O X+D O)$ and (iv) DO. The complexes were cultured individually in IVM media. After 0-4, 10-14 and 20-24 h of culture, the utilization of oxygen, glucose, pyruvate and L-lactate by the complexes was measured. The metabolic activity of the DO was undetectable. There were no significant differences in metabolic measurement among any of the treatment
\end{abstract}

groups, indicating that the metabolism of the cumulus complex is not affected by the presence of the oocyte. When metabolic activity for the complexes was analysed relative to time in culture, there was an approximate twofold increase in the consumption of oxygen, glucose and pyruvate over the $24 \mathrm{~h}$ period $(P<0.05)$, although production of L-lactate remained constant. The relationship between total glucose uptake and L-lactate production indicated that the majority of glucose consumed at the start of culture was being utilized via glycolysis, but by the cessation of the maturation period, there was significant utilization of glucose elsewhere, possibly for the formation of cumulus extracellular matrix. These results indicate that metabolism of COC does not reflect biochemical activity of the oocyte. Nevertheless, the metabolic requirements of the $\mathrm{COC}$ increase throughout maturation.

\section{Introduction}

The environment in which oocytes are cultured during in vitro maturation (IVM) plays an important role in subsequent embryo development. The types and concentrations of energy substrates added to IVM medium alter the metabolic profiles and maturation of oocytes. Glucose, in particular, is an important energy substrate and its addition to medium in appropriate concentrations leads to improved maturation and blastocyst development (Rose-Hellekant et al., 1998; Lim et al., 1999; Khurana and Niemann, 2000; Zheng et al., 2001). Glucose has several fates during IVM: glycolysis leads to the production of ATP and substrates such as pyruvate for further energy production. Alternatively, the metabolism of glucose via the pentose phosphate pathway not only supplies substrates that contribute to ooplasmic integrity,

*Correspondence

Email: jeremy.thompson@adelaide.edu.au but is also linked to the regulation of meiotic maturation within the oocyte (Downs et al., 1998; Downs and Utecht, 1999). Studies focusing on the metabolism of oocytes have shown that during maturation factors that are associated with improved embryo development, such as oocytes collected from adult donors or oocytes matured in vivo, are accompanied by increased glucose utilization through glycolysis and the pentose phosphate pathway, when compared with oocytes from prepubertal donors or oocytes matured in vitro (Gandolfi et al., 1998; Steeves and Gardner, 1999a; Durkin et al., 2001). Furthermore, conditions that promote higher glycolytic activity during IVM also improve developmental capacity (Krisher and Bavister, 1999). Despite cumulus cells playing an important role in the utilization of energy substrates by the oocyte, there is minimal information regarding the metabolic profiles of the cumulus-oocyte complex (COC), and most studies focus on the profiles of denuded oocytes. In the absence of somatic cells, little glucose is utilized by the oocyte (Rieger and 
Loskutoff, 1994; Saito et al., 1994). Hence, the oocyte is reliant on cumulus cells to metabolize glucose to intermediates such as pyruvate, the preferred substrate of the oocyte (Biggers et al., 1967). Therefore, an increased understanding of the metabolic activity of the intact COC may allow the development of improved in vitro maturation conditions and hence improved developmental outcomes.

It is well known that granulosa cells play a critical role in the growth and development of the oocyte. Intercellular communication between cumulus cells and the oocyte occurs via paracrine factors and through gap junctions (Albertini et al., 2001). Cumulus cells facilitate the transfer of nutrients and factors essential for oocyte development, such as metabolites, amino acids, signal transduction molecules and other factors (Colonna and Mangia, 1983; Larsen and Wert, 1988; Buccione et al., 1990a; Eppig, 1991). Cumulus cells also play an important role in the regulation of cytoplasmic and nuclear maturation of the oocyte. For example, the transmission of regulatory molecules such as CAMP and purines via gap junctions allows for the maintenance of meiotic arrest within the oocyte (Eppig and Downs, 1984). Indeed, there is a positive relationship between the developmental potential of the oocyte and cumulus cell morphology, such as cumulus cell compaction (Shioya et al., 1988; Madison et al., 1992; Lonergan et al., 1994; Goud et al., 1998; Khurana and Niemann, 2000), number of cells (Hashimoto et al., 1998) and the degree of expansion.

More recently, the importance of the two-way communication axis between oocytes and granulosa cells has been revealed. Oocytes secrete paracrine growth factors that regulate a broad range of granulosa cell functions by modulating fundamental control elements. For example, oocytes regulate expression of $\mathrm{LH}$ receptors, kit ligand, inhibin subunits and expression of extracellular matrix molecules (Canipari et al., 1995; Eppig et al., 1997; Lanuza et al., 1998; Joyce et al., 1999). As such, oocytes not only promote growth of granulosa cells (Vanderhyden et al., 1992; Gilchrist et al., 2001) and of the follicle, but also regulate differentiation processes such as steroidogenesis and physical remodelling of the follicle (Vanderhyden, 1993; Eppig et al., 2002). The primary recipients of oocyte paracrine signalling are cumulus cells. Cumulus cells have a phenotype that is distinct from that of mural granulosa cells (which line the wall of the follicle), and indeed, maintenance of the cumulus cell phenotype is dependent on oocyte secretions (Eppig et al., 1997; Li et al., 2000). Therefore, paracrine signalling by the oocyte is essential for normal cumulus cell function, as well as for maintaining a functional morphogenic gradient across the ovarian follicle.

As the oocyte regulates such a broad range of cumulus cell functions, it was hypothesized that oocyte paracrine secreted factors would modulate cumulus cell metabolism. As the capacity of the oocyte to utilize glucose is positively correlated with developmental potential, it may be possible to use the metabolic parameters of the cumulus complex as a predictive marker of oocyte quality. The aim of this study was to determine whether oocyte-secreted factors influence the metabolism of the COC.

\section{Materials and Methods}

\section{Materials}

Unless specified, all chemicals and reagents were purchased from Sigma (St Louis, MO).

\section{Collection and culture of oocytes}

Bovine ovaries were collected from a local abattoir and transported to the laboratory in warm $\left(30-35^{\circ} \mathrm{C}\right)$ saline. Follicles, 3-8 $\mathrm{mm}$ in diameter and of non-atretic appearance (Yang and Rajamahendran, 2000), were aspirated using an 18-gauge needle attached to a $10 \mathrm{ml}$ syringe and collected in aspiration media (Hepesbuffered TCM-199 (ICN Biochemicals, Costa Mesa, CA), supplemented with $0.23 \mathrm{mmol}$ sodium pyruvate $\mathrm{I}^{-1}$ and $50.0 \mu \mathrm{g}$ heparin $\mathrm{ml}^{-1}$ ). Complexes from all aspirated oocytes with smooth, ungranulated ooplasm and intact, compact cumulus vestments with more than five cell layers were selected and washed twice in Hepesbuffered TCM-199. COCs were divided randomly into four treatment groups $(n=36$ per treatment): (i) intact COCs, (ii) oocytectomized complexes (OOX), (iii) OOX co-cultured with denuded oocytes (OOX + DO) and (iv) DO. Six replicate experiments were performed. OOX were produced by microsurgical removal of the oocyte, leaving the cumulus cell complex intact (Buccione et al., 1990b), and DO were generated by removing cumulus cells from COCs by vortexing. COC, OOX, OOX + five DO and five DO were then washed in maturation media and cultured individually in pre-equilibrated $10 \mu \mathrm{l}$ drops of maturation media (bicarbonated-buffered TCM199 supplemented with $0.23 \mathrm{mmol}$ sodium pyruvate $\mathrm{I}^{-1}, 4.0 \mathrm{mg}$ BSA $\mathrm{ml}^{-1}$ (ICN Biochemicals), $10.0 \mu \mathrm{g}$ hCG $\mathrm{ml}^{-1}$ (Pregnyl, Organon, Oss) and 20.0 iu FSH $\mathrm{I}^{-1}$ (Puregon, Organon) overlaid with mineral oil and incubated at $39^{\circ} \mathrm{C}$ with $5 \% \mathrm{CO}_{2}$ in humidified air. Culturing OOX together with five DO in a $10 \mu \mathrm{l}$ drop gives a concentration of 0.5 oocyte per $\mu \mathrm{l}$, which is within the typical range used to examine oocyte effects on follicular cells (Gilchrist et al., 2001).

\section{Oxygen consumption assay}

The oxygen consumption of COC, OOX, OOX + DO and DO was assayed at 0-4, 10-14 or 20-24 h of culture. The protocol for the oxygen assay has been described by Houghton et al. (1996) and is based on the fluorescent 
properties of pyrene, an oil soluble compound that is excited at $340 \mathrm{~nm}$, the fluorescence of which dissipates in a linear manner in the presence of increasing oxygen concentrations. Oxygen assay chambers were constructed using $5 \mu \mathrm{l}$ PCR micropipettes (Drummond Scientific Company, Broomall, PA) and a stainless steel plunger. One $\mu \mathrm{l}$ of $1 \mathrm{mmol}$ pyrene $\mathrm{I}^{-1}$ dissolved in mineral oil was drawn into the micropipettes, followed by $2 \mu \mathrm{l}$ Hepes-buffered maturation media containing a single COC, OOX, OOX + one DO, or one DO. An airtight seal was made at the open end of the chamber and the plunger was fixed using sealing wax. Negative control $\left(0 \% \mathrm{O}_{2}\right)$ chambers were constructed in a similar manner, but with $1 \mathrm{mmol}$ oxyrase $\mathrm{I}^{-1}$ (Oxyrase Inc., Mansfield, $\mathrm{OH}$ ) in $60 \mathrm{mmol}$ glucose $\mathrm{I}^{-1}$ (equilibrated overnight to remove $\mathrm{O}_{2}$ ) replacing the media and positive controls $\left(20 \% \mathrm{O}_{2}\right)$ were constructed with media alone. The fluorescence emission of pyrene at the pyrene-media and the pyrene-plunger interfaces were measured using a fluorophotometric-inverted microscope (Leica, Wetzlar). Measurements were taken at intervals of 30 min over a $4 \mathrm{~h}$ period. In between measurements, the chambers were maintained at $39^{\circ} \mathrm{C}$. Oxygen consumption by each complex was determined using a computer program that describes the movement of oxygen from the pyrene-oil into the media as oxygen is consumed by the complex (Houghton et al., 1996). At the completion of the assay, the chambers were dismantled and the complexes and spent media were stored in separate 96-well plates (Falcon) overlaid with mineral oil at $-80^{\circ} \mathrm{C}$.

\section{DNA quantification}

The DNA content of individual complexes or oocytes collected at the completion of the oxygen assay was quantified using PicoGreen dye (Molecular Probes, Eugene, OR), a fluorescent nucleic acid dye that has a high affinity for double-stranded DNA compared with single-stranded DNA and other nucleic acids. Extraction and preparation of the samples and quantification of the DNA were performed entirely in 96-well plates. Total DNA was extracted from complexes by adding $50 \mu \mathrm{l}$ of lysis buffer $\left(50 \mathrm{mmol}\right.$ Tris-HCl I-1, $1 \mathrm{mmol}^{-1}$ EDTA $\mathrm{I}^{-1}$ $\left(\mathrm{pH}\right.$ 7.6), supplemented with $500 \mu \mathrm{g}$ proteinase $\mathrm{K} \mathrm{ml}^{-1}$ ) and incubating for $3.5 \mathrm{~h}$ at $50^{\circ} \mathrm{C}$ and then for $10 \mathrm{~min}$ at $80^{\circ} \mathrm{C}$. Lysates were subsequently treated with $50 \mu \mathrm{l}$ of $10 \mu \mathrm{g}$ DNase-free RNase $\mathrm{ml}^{-1}$ (Roche Diagnostics, Basel) and incubated for $30 \mathrm{~min}$ at $40^{\circ} \mathrm{C}$. Excess liquid was evaporated from the wells and $100 \mu \mathrm{l}$ Tris-EDTA buffer was added to each well. PicoGreen was prepared according to the manufacturer's instructions and added to each sample. Fluorescence was measured using a FLUOstar Galaxy microplate reader and software (BMG Labtechnologies Pty Ltd, Offenburgy) with excitation set at $485 \mathrm{~nm}$ and emission at $520 \mathrm{~nm}$. Standard curves (lambda DNA) were used to determine the DNA content of the samples. The interassay coefficient of variation was $<3 \%$. RNase treatment does not affect DNA concentration or contribute to background fluorescence.

\section{Metabolism assays}

Glucose, L-lactate and pyruvate consumption and production during the oxygen assay were determined by measuring the concentrations of each of the substrates in the spent media using microfluorometric assays (Leese and Barton, 1984; Gardner and Leese, 1986). All of the metabolic measurements were expressed per ng of DNA to account for the variable number of cumulus cells within each complex.

\section{Statistical analyses}

Comparisons of the means of metabolic parameters were performed using two-way ANOVA for the three treatments $(\mathrm{COC}, \mathrm{OOX}$ and $\mathrm{OOX}+\mathrm{DO})$ and the three time-points during maturation. As there were no interactions between time of maturation and treatment group, main effects of time of maturation and treatment are presented. The relationship between glucose uptake and L-lactate production was tested by linear regression analyses. All of the statistical analyses were performed using SigmaStat version 2.0 computer software (SPSS Inc., Chicago, IL).

\section{Results}

The utilization of oxygen, pyruvate, glucose and L-lactate by intact COCs, OOX and OOX + DO was compared at $0-4,10-14$ or $20-24 \mathrm{~h}$ of culture to investigate the relationship between oocyte secreted factors and the metabolic activity of bovine cumulus cell complexes throughout IVM. The metabolism of DO was also measured, but was undetectable for all of the metabolites measured (data not shown). There were no differences in the consumption of oxygen, pyruvate or glucose or production of L-lactate between intact COCs, OOX or OOX + DO (Fig. 1). This finding demonstrates that oocyte secreted factors do not alter metabolic activity of cumulus cells.

At $20-24 \mathrm{~h}$, the consumption of oxygen (Fig. 2a; $94.0 \pm 14.9 \mathrm{pl} \mathrm{ng}^{-1} \mathrm{DNA} \mathrm{h}^{-1}$ ), pyruvate (Fig. 2b; $4.69 \pm 0.85 \mathrm{pmol} \mathrm{ng}^{-1} \mathrm{DNA} \mathrm{h}^{-1}$ ) and glucose (Fig. 2c; $42.4 \pm 6.38 \mathrm{pmol} \mathrm{ng}^{-1} \mathrm{DNA} \mathrm{h}^{-1}$ ) was significantly greater than the consumption at $0-4 \mathrm{~h}$ (oxygen: $50.2 \pm 5.64 \mathrm{pl} \mathrm{ng}^{-1} \mathrm{DNA} \mathrm{h}^{-1}, \quad P=0.026$; pyruvate: $2.15 \pm 0.22 \mathrm{pmol} \mathrm{ng}^{-1} \mathrm{DNA} \mathrm{h}^{-1}, \quad P<0.05 ;$ glucose: $\left.23.5 \pm 3.60 \mathrm{pmol} \mathrm{ng}^{-1} \mathrm{DNA} \mathrm{h}^{-1}, P<0.05\right)$ for oxygen, pyruvate and glucose, respectively). When present at the concentrations used during the present study (5.56 mmol glucose $\mathrm{I}^{-1}$ and $0.23 \mathrm{mmol}$ pyruvate $\mathrm{I}^{-1}$ ) glucose was the preferred substrate throughout the entire culture period, and several-folds more glucose was 

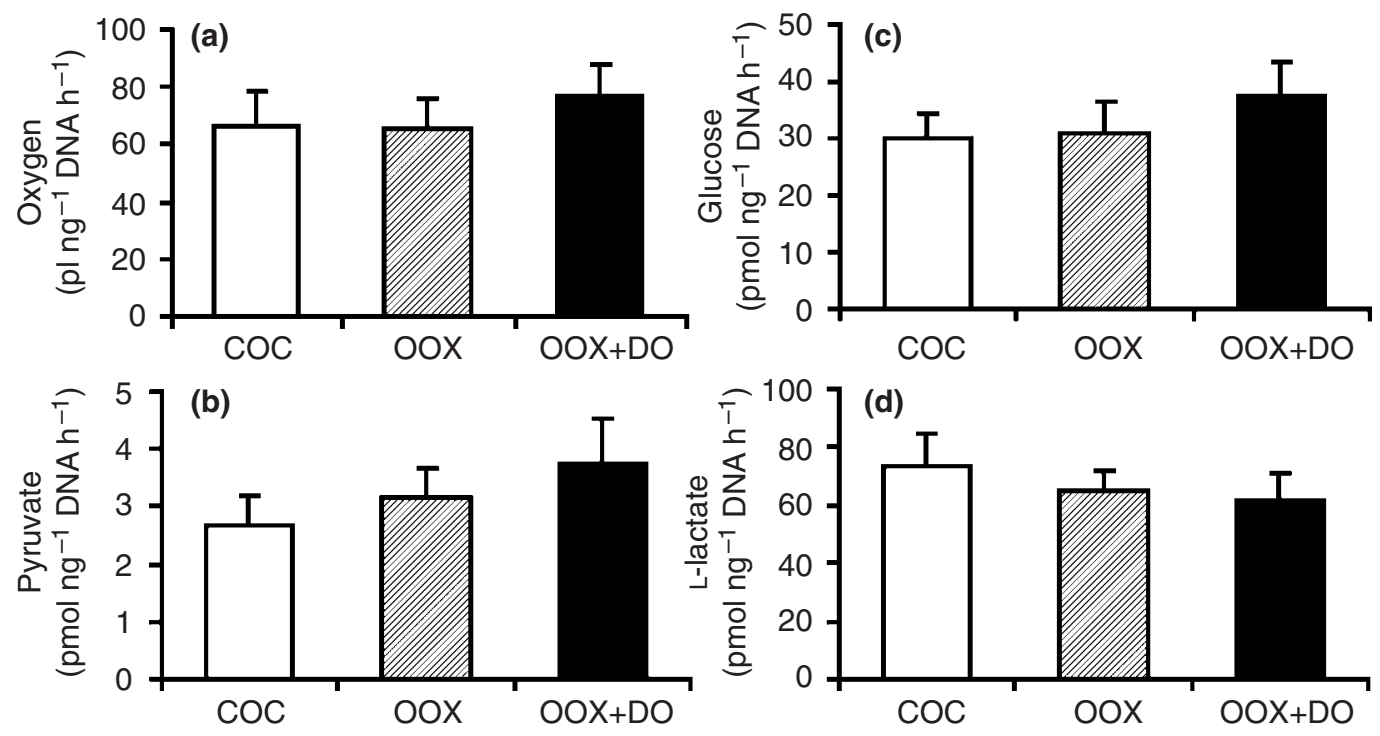

Fig. 1. The influence of oocyte-secreted factors on the metabolism of bovine cumulus cell complexes was determined by measuring the consumption of (a) oxygen, (b) pyruvate and (c) glucose, and (d) the production of L-lactate by intact cumulus-oocyte complexes (COC), oocytectomized complexes (OOX) and OOX cocultured with denuded oocytes $(\mathrm{OOX}+\mathrm{DO})$. Data are expressed per ng of DNA and each bar represents the pooled means \pm SEM. There were no significant differences between any of the treatments for all of the metabolites measured, regardless of culture time.
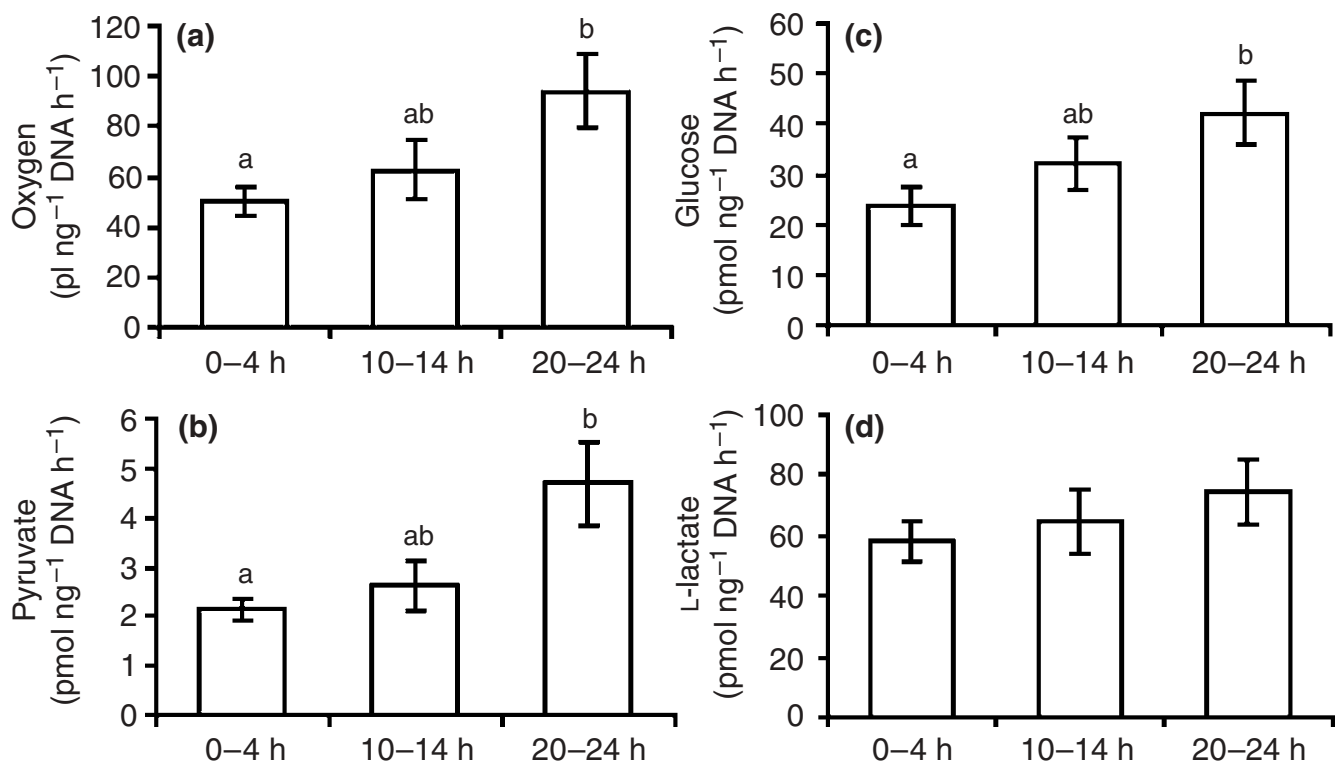

Fig. 2. The utilization of metabolites by bovine cumulus cell complexes was measured at three time points during in vitro maturation. The consumption of (a) oxygen, (b) pyruvate and (c) glucose, and (d) the production of L-lactate were measured. Data are expressed per ng of DNA and each bar represents means \pm SEM. ${ }^{\text {ab } V a l u e s ~ w i t h ~ d i f f e r e n t ~ s u p e r s c r i p t s ~ a r e ~ s i g n i f i c a n t l y ~ d i f f e r e n t ~}(P<0.05)$.

taken up compared with pyruvate. L-lactate was the only metabolite measured in which a net production into the medium was observed and production remained constant over the entire $24 \mathrm{~h}$ culture period (Fig. $2 \mathrm{~d}$ ).

For every molecule of glucose consumed, two molecules of L-lactate are produced via the glycolytic pathway. The relationship between total glucose uptake and L-lactate production was examined at each timepoint to estimate the proportion of glucose being utilized for lactate production. At the beginning of the IVM period, the relationship between glucose and L-lactate was highly significant (Fig. 3a; $P<0.001$, 
(a)
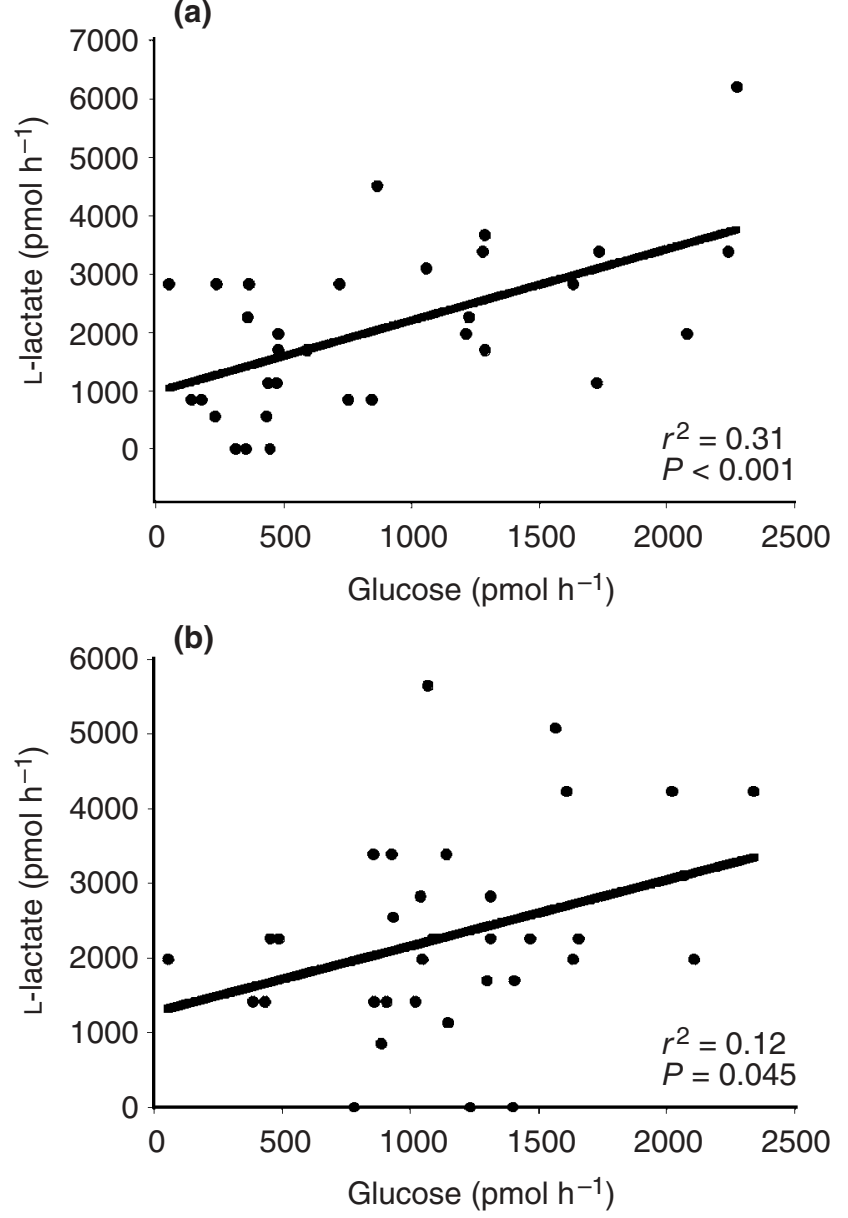

(c)

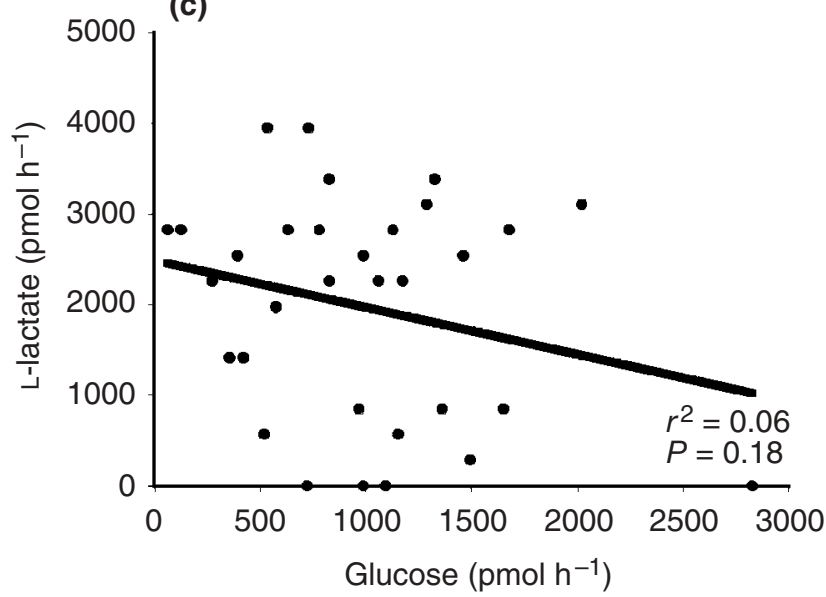

Fig. 3. The relationship between total glucose consumption and L-lactate production by bovine cumulus cell complexes via the glycolytic pathway was examined using linear regression analyses after (a) $0-4 \mathrm{~h}$, (b) $10-14 \mathrm{~h}$ or (c) 20-24 h of culture. Points represent individual complexes.

$r^{2}=0.31$ ), indicating that a large proportion of the glucose consumed was converted to L-lactate at linear rates. At $10-14 \mathrm{~h}$, this relationship was still evident
(Fig. 3b; $P=0.045, r^{2}=0.12$ ), albeit not as pronounced as the relationship at the start of IVM. At 20-24 h, there was no longer a relationship between the rate of glucose consumption and L-lactate production (Fig. 3c; $\left.P=0.178, r^{2}=0.06\right)$. This finding, coupled with the constant L-lactate production over time, indicates that although a substantial proportion of total glucose utilization occurred via glycolysis, increasingly less glucose could be accounted for by L-lactate production, indicating an alternative fate.

In concurrent studies, the IVM system used in the present study resulted in blastocyst production rates of $>40 \%$ (data not shown), demonstrating that oocytes derived from this system behave typically of bovine oocytes matured in vitro.

\section{Discussion}

To date, apart from morphological features, there are no non-invasive methods that can be applied before IVF and in vitro embryo culture to predict the developmental potential of an oocyte. The aim of the present study was to determine whether oocyte-secreted factors (the activity of which may indicate oocyte 'health') influence the metabolism of oxygen, pyruvate, glucose and L-lactate by bovine cumulus cell complexes, as well as to create a metabolic profile of COC metabolism throughout IVM. The present study has demonstrated that the measured metabolic parameters are not affected by the presence of the oocyte. Cumulus complexes that were in physical contact with the oocyte, as well as complexes cocultured with oocytes, had metabolic activities indistinguishable from those of complexes in which the oocyte had been removed (OOX). Furthermore, this was the case at each of the time points measured throughout the IVM period. Oocyte-secreted factors operate in a strictly concentration-dependent manner (Buccione et al., 1990b; Lanuza et al., 1998; Gilchrist et al., 2001), and it is most unlikely that the lack of cumulus cell response to co-culture with oocytes was due to insufficient oocyte factors, as OOX complexes co-cultured with DO at a density of 0.5 oocytes per $\mu \mathrm{l}$ is sufficient to elicit a response in cumulus cells ( $\mathrm{Li}$ et al., 2000; Gilchrist et al., 2001). Furthermore, the lack of difference among treatment groups is unlikely to be due to the insensitivity of the metabolic assays, as these techniques have been used to demonstrate significant differences in the metabolic activity of embryos (Leese and Barton, 1984; Houghton et al., 1996; Thompson et al., 1996).

It is perhaps surprising that oocytes do not seem to regulate cumulus cell metabolism, given that, in general, the oocyte plays a role in the regulation of most cumulus cell functions that have been examined to date (Eppig, 2001). However, there are precedents for cumulus cell activities that are independent of oocyte regulation. Most 
notably, FSH-stimulated expansion of pig and bovine COC occurs independently of the oocyte (Prochazka et al., 1991; Singh et al., 1993; Ralph et al., 1995; Nagyova et al., 1999). However, this is a species-specific phenomenon as rodent COC mucification is absolutely dependent on the presence of the oocyte (Buccione et al., 1990b; Salustri et al., 1990). In addition, it has been demonstrated that pig oocytes secrete factors that enable the expansion of both rat and mice cumulus cells (Vanderhyden, 1993; Nagyova et al., 2000).

The observation that the metabolic activity of the cumulus cell is independent of the oocyte is in contrast to previous studies that demonstrated that $\mathrm{LH}$ increased glycolytic activity in intact bovine COC, but not in OOX (Zuelke and Brackett, 1992). However, there are numerous differences between the two studies. For example, the source of $\mathrm{LH}$ was different and the IVM media used in the present study contained hCG, whereas Zuelke and Brackett (1992) used bovine LH purified from pituitary extracts. In addition, total glucose uptake was measured throughout IVM, compared with the activities of specific pathways at the end of IVM (Zuelke and Brackett, 1992). The present study demonstrated that by $24 \mathrm{~h}$ of culture, a large proportion of the glucose consumed was not utilized via glycolysis. It is possible that only the specific glycolytic pathway that was examined in the previous study is affected by oocytesecreted factors.

The fact that the metabolic activities of cumulus cells were independent of oocyte-secreted factors indicates that the non-invasive measurements of substrate consumption or production by COCs used in the present study cannot be used to determine the biochemical activity (that is health) of an oocyte. This finding indicates that acquisition of developmental competence of bovine oocytes may also not be determined by such factors. This is also the case in feline oocytes, in which increased glucose metabolism is positively correlated with developmental potential; whereas the metabolism of cumulus cells removed before fertilization was not indicative of the developmental potential of the oocyte from which they originated (Spindler et al., 2000). It is plausible that features of the in vivo environment such as follicle size, classification (that is subordinate or dominant), health or stage of the oestrous cycle of the donor at collection have a greater influence on developmental potential, as these factors have been associated with improved embryo development (Blondin and Sirard, 1995; Hagemann, 1999; Hagemann et al., 1999).

The metabolic activity of the COC as a whole has not been widely characterized to date, as most studies have focused on the utilization of substrates by the oocyte. As the presence of the cumulus cell vestment is essential to oocyte maturation, the metabolism of the intact COC throughout IVM was investigated as opposed to that of the denuded oocyte alone. Although the oocyte does not have an effect on the metabolism of the complex, the increased requirement for glucose during the maturation period is in agreement with the reported metabolic profile of the denuded oocyte (Rieger and Loskutoff, 1994; Steeves and Gardner, 1999b). Pyruvate consumption by COCs is also positively related to nuclear maturation (Downs et al., 2002); hence increased culture time leads to higher requirements for pyruvate by the oocyte. Glycolysis was the predominant pathway for glucose utilization, as L-lactate production accounted for most of the glucose consumed. The oxygen uptake (which is indicative of oxidative phosphorylation) can be accounted for by the uptake of pyruvate (and subsequent utilization through the tricarboxylic acid cycle).

The constant rate of L-lactate production throughout IVM indicates that the proportion of consumed glucose that was utilized for ATP production via glycolysis for the COC did not change over the $24 \mathrm{~h}$ of culture. This finding is in agreement with the observation that phosphofructokinase activity (the rate limiting enzyme of glycolysis) remains constant throughout oocyte maturation (Cetica et al., 2002). There are numerous pathways through which glucose can be used, and it is possible that during different stages of oocyte maturation, there are different requirements for the substrates that were measured. Previous studies have demonstrated that the pentose phosphate pathway is active throughout maturation and there is a positive relationship between increased glucose flux through this pathway and the induction of meiosis (Downs et al., 1998). It is possible that towards the end of IVM the flux of glucose through the pentose phosphate pathway increases to allow for increased production of substrates involved in nuclear maturation. An additional route of glucose utilization is the conversion of glucose to extracellular matrix components. A large component of cumulus expansion is the increased synthesis of extracellular matrix, which is not only an energy expensive process but also requires the synthesis of matrix components. Glucose metabolized by cumulus cells can be utilized via the glycolytic pathway for energy production, but may also be used for the synthesis of glucosamine, a substrate for hyaluronic acid (Chen et al., 1993), a major component of cumulus matrix. These pathways are most likely linked, as the addition of FSH has been associated with increased glucose consumption (Downs and Utecht, 1999) and mucification (Salustri et al., 1989). Mucification occurs in the latter part of maturation and is important in vivo for the events after ovulation (Chen et al.,1993). Therefore, it is more likely that the increased glucose uptake towards the end of IVM observed in this study is attributed to an increased extracellular matrix formation, particularly as pentose phosphate pathway activity has been shown to be low compared with glycolytic activity (Urner and Sakkas, 1999). Investigations are currently in progress to analyse further the role of glucose in cumulus matrix formation in the COC. 
In conclusion, the present study has demonstrated that the metabolism of oxygen, pyruvate, glucose and L-lactate by bovine cumulus cell complexes is not affected by oocyte-secreted factors, hence non-invasive measurements of the utilization of these substrates by COCs is unlikely to represent biochemical activities of the oocyte associated with developmental competence. In addition, the present study has demonstrated that the metabolic requirements of the COC increased through IVM. It is possible that further investigation of the metabolism of the COC as a unit may aid in the optimization of culture conditions during IVM.

The authors thank R. Collett for technical assistance and J. Hayes for the ovary collections. M. Sutton is supported by the Australia Research Council (SPIRT, C00107702) and Cook Australia Pty Ltd. P. Cetica would like to thank the School of Veterinary Sciences, University of Buenos Aires and the Reproductive Medicine Unit of The Queen Elizabeth Hospital for the financial support of his postdoctoral research.

\section{References}

Albertini DF, Combelles CM, Benecchi E and Carabatsos MJ (2001) Cellular basis for paracrine regulation of ovarian follicle development Reproduction 121 647-653

Biggers JD, Whittingham DG and Donahue RP (1967) The pattern of energy metabolism in the mouse oocyte and zygote Zoology 58 560-567

Blondin P and Sirard MA (1995) Oocyte and follicular morphology as determining characteristics for developmental competence in bovine oocytes Molecular Reproduction and Development 41 54-62

Buccione R, Schroeder AC and Eppig JJ (1990a) Interactions between somatic cells and germ cells throughout mammalian oogenesis Biology of Reproduction 43 543-547

Buccione R, Vanderhyden BC, Caron PJ and Eppig JJ (1990b) FSH-induced expansion of the mouse cumulus oophorus in vitro is dependent upon a specific factor(s) secreted by the oocyte Developmental Biology 138 $16-25$

Canipari R, Epifano O, Siracusa G and Salustri A (1995) Mouse oocytes inhibit plasminogen activator production by ovarian cumulus and granulosa cells Developmental Biology $167371-378$

Cetica P, Pintos L, Dalvit G and Beconi M (2002) Activity of key enzymes involved in glucose and triglyceride catabolism during bovine oocyte maturation in vitro. Reproduction 124 675-681

Chen L, Russell PT and Larsen WJ (1993) Functional significance of cumulus expansion in the mouse: roles for the preovulatory synthesis of hyaluronic acid within the cumulus mass Molecular Reproduction and Development 34 87-93

Colonna R and Mangia F (1983) Mechanisms of amino acid uptake in cumulus-enclosed mouse oocytes Biology of Reproduction 28 797-803

Downs SM and Utecht AM (1999) Metabolism of radiolabeled glucose by mouse oocytes and oocyte-cumulus cell complexes Biology of Reproduction 60 1446-1452

Downs SM, Humpherson PG and Leese HJ (1998) Meiotic induction in cumulus cell-enclosed mouse oocytes: involvement of the pentose phosphate pathway Biology of Reproduction 58 1084-1094

Downs SM, Humpherson PG and Leese HJ (2002) Pyruvate utilization by mouse oocytes is influenced by meiotic status and the cumulus oophorus Molecular Reproduction and Development 62 113-123

Durkin RE, Swain JE, Bormann CL, Frederick AM and Krisher RL (2001) Metabolism of porcine oocytes matured in vivo and in vitro. Biology of Reproduction 64 Supplement 1 (Abstract 81)

Eppig JJ (1991) Intercommunication between mammalian oocytes and companion somatic cells Bioessays 13 569-574
Eppig JJ (2001) Oocyte control of ovarian follicular development and function in mammals Reproduction 122 829-838

Eppig JJ and Downs SM (1984) Chemical signals that regulate mammalian oocyte maturation Biology of Reproduction 30 1-11

Eppig JJ, Wigglesworth K, Pendola F and Hirao Y (1997) Murine oocytes suppress expression of luteinizing hormone receptor messenger ribonucleic acid by granulosa cells Biology of Reproduction 56 976-984

Eppig JJ, Wigglesworth K and Pendola FL (2002) The mammalian oocyte orchestrates the rate of ovarian follicular development Proceedings National Academy of Sciences USA 99 2890-2894

Gandolfi F, Milanesi E, Pocar P, Luciano AM, Brevini TA, Acocella F, Lauria A and Armstrong DT (1998) Comparative analysis of calf and cow oocytes during in vitro maturation Molecular Reproduction and Development 49 168-175

Gardner DK and Leese HJ (1986) Non-invasive measurement of nutrient uptake by single cultured pre-implantation mouse embryos Human Reproduction 1 25-27

Gilchrist RB, Ritter LJ and Armstrong DT (2001) Mouse oocyte mitogenic activity is developmentally coordinated throughout folliculogenesis and meiotic maturation Developmental Biology 240 289-298

Goud PT, Goud AP, Qian C, Laverge H, Van der Elst J, De Sutter P and Dhont M (1998) In vitro maturation of human germinal vesicle stage oocytes: role of cumulus cells and epidermal growth factor in the culture medium Human Reproduction 13 1638-1644

Hagemann LJ (1999) Influence of the dominant follicle on oocytes from subordinate follicles Theriogenology 51 449-459

Hagemann LJ, Beaumont SE, Berg M, Donnison MJ, Ledgard A, Peterson AJ, Schurmann A and Tervit HR (1999) Development during single IVP of bovine oocytes from dissected follicles: interactive effects of estrous cycle stage, follicle size and atresia Molecular Reproduction and Development $\mathbf{5 3}$ 451-458

Hashimoto S, Saeki K, Nagao Y, Minami N, Yamada M and Utsumi K (1998) Effects of cumulus cell density during in vitro maturation on the developmental competence of bovine oocytes Theriogenology $\mathbf{4 9}$ 1451-1463

Houghton FD, Thompson JG, Kennedy CJ and Leese HJ (1996) Oxygen consumption and energy metabolism of the early mouse embryo Molecular Reproduction and Development 44 476-485

Joyce IM, Pendola FL, Wigglesworth K and Eppig JJ (1999) Oocyte regulation of kit ligand expression in mouse ovarian follicles Developmental Biology 214 342-353

Khurana NK and Niemann H (2000) Effects of oocyte quality, oxygen tension, embryo density, cumulus cells and energy substrates on cleavage and morula/blastocyst formation of bovine embryos Theriogenology 54 741-756

Krisher RL and Bavister BD (1999) Enhanced glycolysis after maturation of bovine oocytes in vitro is associated with increased developmental competence Molecular Reproduction and Development 53 19-26

Lanuza GM, Fischman ML and Baranao JL (1998) Growth promoting activity of oocytes on granulosa cells is decreased upon meiotic maturation Developmental Biology 197 129-139

Larsen WJ and Wert SE (1988) Roles of cell junctions in gametogenesis and in early embryonic development Tissue and Cell 20 809-848

Leese HJ and Barton AM (1984) Pyruvate and glucose uptake by mouse ova and preimplantation embryos Journal of Reproduction and Fertility $\mathbf{7 2}$ 9-13

Li R, Norman RJ, Armstrong DT and Gilchrist RB (2000) Oocytesecreted factor(s) determine functional differences between bovine mural granulosa cells and cumulus cells Biology of Reproduction $\mathbf{6 3}$ 839-845

Lim JM, Lee BC, Lee ES, Chung HM, Ko JJ, Park SE, Cha KY and Hwang WS (1999) In vitro maturation and in vitro fertilization of bovine oocytes cultured in a chemically defined, protein-free medium: effects of carbohydrates and amino acids Reproduction, Fertility and Development 11 127-132

Lonergan P, Monaghan P, Rizos D, Boland MP and Gordon I (1994) Effect of follicle size on bovine oocyte quality and developmental competence following maturation, fertilization and culture in vitro. Molecular Reproduction and Development 37 48-53 
Madison V, Avery B and Greve T (1992) Selection of immature bovine oocytes for developmental potential in vitro. Animal Reproduction Science 27 1-11

Nagyova E, Prochazka R and Vanderhyden BC (1999) Oocytectomy does not influence synthesis of hyaluronic acid by pig cumulus cells: retention of hyaluronic acid after insulin-like growth factor I treatment in serum-free medium Biology of Reproduction 61 569-574

Nagyova E, Vanderhyden BC and Prochazka R (2000) Secretion of paracrine factors enabling expansion of cumulus cells is developmentally regulated in pig oocytes Biology of Reproduction 63 1149-1156

Prochazka R, Nagyova E, Rimkevicova Z, Nagai T, Kikuchi K and Motlik J (1991) Lack of effect of oocytectomy on expansion of the porcine cumulus Journal of Reproduction and Fertility 93 569-576

Ralph JH, Telfer EE and Wilmut I (1995) Bovine cumulus cell expansion does not depend on the presence of an oocyte secreted factor Molecular Reproduction and Development 42 248-253

Rieger D and Loskutoff NM (1994) Changes in the metabolism of glucose, pyruvate, glutamine and glycine during maturation of cattle oocytes in vitro. Journal of Reproduction and Fertility 100 257-262

Rose-Hellekant TA, Libersky-Williamson EA and Bavister BD (1998) Energy substrates and amino acids provided during in vitro maturation of bovine oocytes alter acquisition of developmental competence Zygote 6 285294

Saito T, Hiroi M and Kato T (1994) Development of glucose utilization studied in single oocytes and preimplantation embryos from mice Biology of Reproduction 50 266-270

Salustri A, Yanagishita M and Hascall VC (1989) Synthesis and accumulation of hyaluronic acid and proteoglycans in the mouse cumulus cell-oocyte complex during follicle-stimulating hormone-induced mucification Journal of Biological Chemistry 26413 840-13 847

Salustri A, Yanagishita M and Hascall VC (1990) Mouse oocytes regulate hyaluronic acid synthesis and mucification by $\mathrm{FSH}$-stimulated cumulus cells Developmental Biology 138 26-32

Shioya Y, Kuwayama M, Fukushima $\mathbf{M}$ and Iwasaki S (1988) In vitro fertilization and cleavage capability of bovine follicular oocytes classsified by cumulus cells and matured in vitro. Theriogenology $\mathbf{3 0}$ 489-496

Singh B, Zhang X and Armstrong DT (1993) Porcine oocytes release cumulus expansion-enabling activity even though porcine cumulus expansion in vitro is independent of the oocyte Endocrinology 132 1860-1862
Spindler RE, Pukazhenthi BS and Wildt DE (2000) Oocyte metabolism predicts the development of cat embryos to blastocyst in vitro. Molecular Reproduction and Development 56 163-171

Steeves TE and Gardner DK (1999a) Temporal and differential effects of amino acids on bovine embryo development in culture Biology of Reproduction 61 731-740

Steeves TE and Gardner DK (1999b) Metabolism of glucose, pyruvate and glutamine during the maturation of oocytes derived from pre-pubertal and adult cows Molecular Reproduction and Development 54 92-101

Thompson JG, Partridge RJ, Houghton FD, Cox CI and Leese HJ (1996) Oxygen uptake and carbohydrate metabolism by in vitro derived bovine embryos Journal of Reproduction and Fertility 106 299-306

Urner F and Sakkas D (1999) Characterization of glycolysis and pentose phosphate pathway activity during sperm entry into the mouse oocyte Biology of Reproduction 60 973-978

Vanderhyden BC (1993) Species differences in the regulation of cumulus expansion by an oocyte-secreted factor(s) Journal of Reproduction and Fertility 98 219-227

Vanderhyden BC, Telfer EE and Eppig JJ (1992) Mouse oocytes promote proliferation of granulosa cells from preantral and antral follicles in vitro. Biology of Reproduction 46 1196-1204

Yang MY and Rajamahendran R (2000) Morphological and biochemical identification of apoptosis in small, medium, and large bovine follicles and the effects of follicle-stimulating hormone and insulin-like growth factor I on spontaneous apoptosis in cultured bovine granulosa cells Biology of Reproduction 62 1209-1217

Zheng P, Bavister BD and Ji W (2001) Energy substrate requirement for in vitro maturation of oocytes from unstimulated adult rhesus monkeys Molecular Reproduction and Development 58 348-355

Zuelke KA and Brackett BG (1992) Effects of luteinizing hormone on glucose metabolism in cumulus-enclosed bovine oocytes matured in vitro. Endocrinology 131 2690-2696

Received 22 January 2003.

First decision 10 March 2003.

Revised manuscript received 13 March 2003.

Accepted 13 March 2003. 